\title{
The nature of apraxia in corticobasal degeneration
}

\author{
R Leiguarda, A J Lees, M Merello, S Starkstein, C D Marsden
}

\begin{abstract}
Although apraxia is one of the most frequent signs in corticobasal degeneration, the phenomenology of this disorder has not been formally examined. Hence 10 patients with corticobasal degeneration were studied with a standardised evaluation for different types of apraxia. To minimise the confounding effects of the primary motor disorder, apraxia was assessed in the least affected limb. Whereas none of the patients showed buccofacial apraxia, seven showed deficits on tests of ideomotor apraxia and movement imitation, four on tests of sequential arm movements (all of whom had ideomotor apraxia), and three on tests of ideational apraxia (all of whom had ideomotor apraxia). Ideomotor apraxia significantly correlated with deficit in both the mini mental state examination and in a task sensitive to frontal lobe dysfunction (picture arrangement). Two of the three patients with ideomotor apraxia and ideational apraxia showed severe cognitive impairments. The alien limb behaviour was present only in patients with ideomotor apraxia. In conclusion, ideomotor apraxia is the most frequent type of apraxia in corticobasal degeneration, and may be due to dysfunction of the supplementary motor area. There is a subgroup of patients with corticobasal degeneration who have a severe apraxia (ideomotor and ideational apraxia), which correlates with global cognitive impairment, and may result from additional parietal or diffuse cortical damage.
\end{abstract}

of Neurological

Research, FLENI,

Buenos Aires,

Argentina

R Leiguarda

M Merello

S Starkstein

Institute of Neurology,

National Hospital for

Neurology and

Neurosurgery, Queen

Square, London, UK

A J Lees

$M$ Merello

C D Marsden

Correspondence to:

Dr Ramón Leiguarda,

FLENI, Ayacucho 2166,

(1112) Buenos Aires,

Argentina.

Received 12 April 1993

and in revised form

7 June 1993.

Accepted 28 July 1993 shows a combination of parietal and frontal hypometabolism and an asymmetrical decrease of fluorodopa uptake in the striatum and medial frontal cortex. ${ }^{378}$

When fully developed, the disorder has a distinctive clinical picture, but the initial manifestations of basal ganglia dysfunction may be confused with other akinetic-rigid syndromes. Therefore, findings such as apraxia are essential for the clinical diagnosis. ${ }^{157}$

The pathological process in corticobasal degeneration affects many brain structures involved in praxic functions (parietal and non-primary motor cortex). Apraxia has been described in about $80 \%$ of patients, but the nature of this deficit has not been systematically examined. ${ }^{1-8}$ We have tested 10 patients with corticobasal degeneration for the presence of buccofacial apraxia, ideomotor apraxia, and ideational apraxia, and have correlated these phenomena with other cardinal features of the disorder. One important limitation in the evaluation of limb apraxia in corticobasal degeneration is how to assess this disorder in the presence of an akinetic-rigid syndrome and involuntary movements. To minimise this problem we only examined praxic functions in the less affected limb.

\section{Patients and methods}

Ten patients with corticobasal degeneration were studied (table 1). Criteria for diagnosis were the insidious onset and gradual progression of an asymmetric levodopa-resistant akinetic-rigid syndrome, with or without other basal ganglia features (dystonia, tremor), associated with signs of cortical dysfunction such as cortical sensory loss, alien limb, or apraxia.

Apraxia was evaluated by a neurologist with a structured assessment. Gestures were scored as apraxic only when: (1) no abnormal involuntary movements (for example tremor, dystonia, myoclonus) coincided with the motor response; (2) comprehension of the command was normal; (3) patients could properly name all the objects tested; and (4) the abnormal response was not corrected after verbal instructions were repeated once.

\section{BUCCOFACIAL APRAXIA}

Patients were asked to perform 10 gestures (for example, stick out the tongue, blow out a match, sniff a flower), and were given three points when the movement was accurately performed; two points when correct only after 
Table 1 Clinical features in 10 patients with corticobasal degeneration

\begin{tabular}{|c|c|c|c|c|c|c|c|c|c|c|}
\hline & \multicolumn{10}{|c|}{ Patients } \\
\hline & 1 & 2 & 3 & 4 & 5 & 6 & 7 & 8 & 9 & 10 \\
\hline $\begin{array}{l}\text { Age (y) } \\
\text { Sex } \\
\text { Handedness } \\
\text { Disease duration (y) } \\
\text { Side of initial symptoms }\end{array}$ & $\begin{array}{l}69 \\
F \\
R \\
4 \\
L\end{array}$ & $\begin{array}{l}61 \\
M \\
R \\
3\end{array}$ & $\begin{array}{l}78 \\
\mathrm{M} \\
\mathrm{R} \\
5 \\
\mathrm{R}\end{array}$ & $\begin{array}{l}78 \\
F \\
R \\
4 \\
L\end{array}$ & $\begin{array}{l}58 \\
F \\
R \\
3\end{array}$ & $\begin{array}{l}78 \\
M \\
R \\
3 \\
R\end{array}$ & $\begin{array}{l}69 \\
\mathrm{~F} \\
\mathrm{R} \\
5 \\
\mathrm{R}\end{array}$ & $\begin{array}{l}72 \\
F \\
R \\
5\end{array}$ & $\begin{array}{l}69 \\
\mathrm{~F} \\
\mathrm{R} \\
4 \\
\mathrm{R}\end{array}$ & $\begin{array}{l}61 \\
M \\
R \\
6 \\
R\end{array}$ \\
\hline $\begin{array}{l}\text { Akinesia, rigidity } \\
\text { Postural instability, falls } \\
\text { Dystonia } \\
\text { Myoclonus } \\
\text { Tremor (postural, action) }\end{array}$ & $\begin{array}{l}+ \\
+ \\
+ \\
+ \\
+\end{array}$ & $\begin{array}{l}+ \\
- \\
+ \\
-\end{array}$ & $\begin{array}{l}+ \\
+ \\
+ \\
+ \\
+\end{array}$ & $\begin{array}{l}+ \\
+ \\
+ \\
- \\
-\end{array}$ & $\begin{array}{l}+ \\
+ \\
+ \\
+\end{array}$ & $\begin{array}{l}+ \\
+ \\
+ \\
+ \\
+\end{array}$ & $\begin{array}{l}+ \\
+ \\
+ \\
+ \\
+\end{array}$ & $\begin{array}{l}+ \\
+ \\
+ \\
+\end{array}$ & $\begin{array}{l}+ \\
+ \\
+ \\
+ \\
+\end{array}$ & $\begin{array}{l}+ \\
+ \\
+ \\
-\end{array}$ \\
\hline $\begin{array}{l}\text { Cortical sensory loss } \\
\text { Apraxia } \\
\text { Visuoconstructive disability } \\
\text { Alien limb } \\
\text { Dysphasia } \\
\text { Dementia } \\
\text { Frontal dysfunction }\end{array}$ & $\begin{array}{l} \pm \\
\pm \\
- \\
- \\
- \\
-\end{array}$ & $\begin{array}{l}+ \\
- \\
- \\
- \\
-\end{array}$ & $\begin{array}{l}- \\
+ \\
\overline{+} \\
+ \\
\overline{+}\end{array}$ & $\begin{array}{l}- \\
+ \\
- \\
- \\
- \\
- \\
+\end{array}$ & $\begin{array}{l}+ \\
- \\
- \\
- \\
- \\
-\end{array}$ & $\begin{array}{l}+ \\
+ \\
- \\
+ \\
- \\
+\end{array}$ & $\begin{array}{l}+ \\
+ \\
+ \\
+ \\
+ \\
+ \\
+\end{array}$ & $\begin{array}{l}+ \\
+ \\
+ \\
+ \\
+ \\
+ \\
+\end{array}$ & $\begin{array}{l}- \\
+ \\
- \\
+ \\
- \\
-\end{array}$ & $\begin{array}{l}+ \\
+ \\
+ \\
+ \\
- \\
-\end{array}$ \\
\hline $\begin{array}{l}\text { Supranuclear gaze palsy } \\
\text { Hyperreflexia } \\
\text { Primitive reflexes } \\
\text { Babinski sign } \\
\text { Dysarthria } \\
\text { Dysphagia }\end{array}$ & $\begin{array}{l}- \\
+ \\
\overline{+} \\
- \\
-\end{array}$ & $\begin{array}{l}- \\
+ \\
+ \\
+ \\
+\end{array}$ & $\begin{array}{l}- \\
+ \\
\overline{-} \\
- \\
-\end{array}$ & $\begin{array}{l}+ \\
- \\
- \\
- \\
+\end{array}$ & $\begin{array}{l}+ \\
- \\
- \\
+ \\
+\end{array}$ & $\begin{array}{l}- \\
\overline{+} \\
\overline{+} \\
+ \\
-\end{array}$ & $\begin{array}{l}+ \\
+ \\
+ \\
+ \\
+ \\
-\end{array}$ & $\begin{array}{l}- \\
+ \\
+ \\
- \\
- \\
-\end{array}$ & $\begin{array}{l}- \\
+ \\
+ \\
- \\
+ \\
-\end{array}$ & $\begin{array}{l}+ \\
+ \\
+ \\
+ \\
- \\
-\end{array}$ \\
\hline
\end{tabular}

imitation; one point when the correct performance was preceded by pauses, or the overall gesture was acceptable though defective in terms of amplitude, force and speed; and zero points when the gesture was incomplete or irrelevant, there was perseveration, or no oral movements were carried out (total score 30 ).

\section{IDEOMOTOR APRAXIA}

Patients were asked to perform with the least affected limb 10 intransitive movements (for example, wave goodbye, snap the fingers, hitch hike) and 10 transitive movements (for example, use a hammer, use a screwdriver, use a key) in either verbal, visual or tactile modalities, and on imitation. Maximum score for intransitive movements was 20. For every item, two points were scored for a correct performance; one point when the correct performance was preceded by hesitation or a repeated trial; and zero points when the requested gesture was not or only partially performed. For transitive movements, patients were given three points whenever the performance was appropriate for the object; two points when the performance resembled the correct one but included different types of errors (see later); one point when the movement had a weak resemblance to the appropriate gesture; and zero points when the gesture was so wrong or incomplete as to be unrecognisable, or there was a complete failure to carry out the command (maximum score for transitive movements: 30 points). Four types of errors were considerednamely, content, temporal, spatial, and others. ${ }^{9}$ Delay in initiation, timing, and amplitude errors were not considered. Content errors, lack of response, and unrecognisable movements were not scored as ideomotor apraxia. Ideomotor apraxia was present whenever patients made two or more unequivocal errors. The severity of apraxia was rated as mild (41 to 50 points), moderate ( 25 to 40 points), or severe ( $<25$ points).

\section{IDEATIONAL APRAXIA}

Patients were asked to carry out three multiple step tasks. For the first task, patients were given a flashlight and two batteries, and were asked to take the proper steps to turn on the bulb. Thus patients were supposed to unscrew the bottom of the flashlight (step 1), introduce the batteries (step 2), and turn on the light (step 3). For the second task, patients were given a closed padlock and the corresponding key, and were asked to open the padlock with the key and close it again. The steps were first, to introduce the key in the padlock and open it, second to take the key out, and third to close the padlock (the padlock would not close with the key in). Finally, patients were given a piece of paper, an open envelope, and a stamp, and were asked to mail the letter. The steps were first, to fold the paper, second to put the paper into the envelope and close the envelope, and third to glue the stamp to the envelope. The alternative sequences of glueing the stamp before folding the paper or putting the paper into the envelope were also considered as correct. As patients had to use both hands to perform these movements, we were not interested in the correct performance of each step in terms of the accuracy of individual movements, but in the overall performance of the task sequence. Therefore, if the patient had a motor deficit that precluded the execution of an action that required bimanual coordination (for example, unscrewing the bottom of the flashlight), the examiner assisted him or her by holding the object or completing part of the action after the sequence was pointed out by the patient. Scoring was based on the number of errors, which included lack of response, a verbal response instead of the actual movement, perplexity, omissions, mislocation of steps, misuse of objects, and sequence errors. Ideational apraxia was rated as mild when patients made up to three errors, moderate with four to six errors, and 
severe with more than six errors. When tested for ideomotor apraxia patients were also asked to recognise gestures. In the discrimination task (10 items), the examiner named a target stimulus and pantomimed the correct act as well as two foils. One foil was a clumsily performed movement, and the other used a body part as object (for instance, moving fingers as if they were scissor blades). Patients were also asked to name the gesture performed by the examiner (for example, hammering) (10 trials). More than one error on gesture discrimination and/or on gesture comprehension was considered abnormal.

To compare ideomotor apraxia with impaired performance of non-symbolic and sequence movements, movement imitation, and complex arm movement tests were also carried out. Four subtests of three gestures each, evaluating the ability to imitate different positions and sequences of fingers and hands (making a circle with the thumb and index fingers, and a hand-chest sequence) were presented. Scores ranged from zero to three for each gesture, and the maximum score was 36 . The severity of the disorder was rated as mild (27 to 35 points), moderate (15 to 26 points), or severe ( $<15$ points). The ability to perform six different complex sequential arm movements in response to verbal commands (for example, close fist, thump sideways on table, slap down on table) were also tested. Types of errors included perplexity, sequence errors, intrusions, and omissions. Two points were assigned to a correct response; one point to a partially correct response; and zero points when the response was incorrect or absent. The maximum score was 12 and the disorder was rated as mild (six to 10 points), moderate (four to five points), or severe ( $<4$ points).

Global cognitive decline was measured with the mini mental state examination (MMSE), an 11-item examination found to be reliable and valid in assessing a limited range of cognitive functions. We have also assessed the picture arrangement test of the Wechsler adult intelligence scale as a measure of planning and abstraction. The picture arrangement test consists of sets of pictures in a jumbled order, and the patient is asked to arrange them in an order that tells a sensible story. This test requires picture comprehension and abstract thinking in a sensible sequence. Maximum score is 20 points. The final score did not consider time to completion.
Statistical analyses were carried out on means and standard deviations with Fisher's exact test, Student's $t$ tests, and regression analysis.

\section{Results}

Table 2 shows the results of apraxia evaluations, movement imitation, and complex arm movement tests, MMSE scores, and picture arrangement scores.

None of the 10 patients had buccofacial apraxia. Seven patients had ideomotor apraxia, four of whom (cases 3, 4, 9, and 10) could properly recognise and visually discriminate gestures performed by the examiner, whereas three (cases 6,7 , and 8) had comprehension or discrimination deficits. In decreasing order of frequency, the principal error types were internal configuration or postural, orientation, sequencing, body-part as object, and trajectory.

Whereas abnormalities of movement imitation were found in all seven patients with ideomotor apraxia, deficits in sequential arm movements were seen in only four, who also had the most severe praxic disturbances. Three patients (cases 6, 7, and 8) showed both ideomotor apraxia and ideational apraxia. Errors due to ideational apraxia most often identified were perplexity, absent or unrecognisable response, omissions, sequence errors, and mislocations. When side of initial symptoms was considered, all five patients who showed initial symptoms on the right side had ideomotor apraxia as compared with two of the five patients who showed initial symptoms on the left side. A hypothesis of unequal frequency of the presence of ideomotor apraxia based on the side of initial symptoms was statistically substantiated $\left(\chi^{2}=\right.$ 4.29, $\mathrm{df}=1, \mathrm{p}<0.05)$.

A stepwise regression analysis with ideomotor apraxia scores as the dependent variable and MMSE scores, picture arrangement scores, age, and duration of illness as independent variables showed significant correlations between ideomotor apraxia scores and both MMSE scores $\left(R^{2}=0.83, F(1,8)=\right.$ $40.0, p<0.01$ ), and picture arrangement scores $\left(R^{2}=0.95, F(2,7)=72 \cdot 5, p<0.01\right)$. No significant correlations were found between ideomotor apraxia scores and age or duration of illness. When movement imitation scores were entered as the dependent variable, similar results were obtained

Table 2 Results of apraxia evaluation, movement imitation, complex arm movements tests, MMSE, and picture arrangement

\begin{tabular}{|c|c|c|c|c|c|c|c|c|c|c|}
\hline & \multicolumn{10}{|l|}{ Patients } \\
\hline & 1 & 2 & 3 & 4 & 5 & 6 & 7 & 8 & 9 & 10 \\
\hline $\begin{array}{l}\text { Buccofacial apraxia } \\
\text { Ideomotor apraxia: }\end{array}$ & - & - & - & - & - & - & - & - & - & - \\
\hline $\begin{array}{l}\text { Production } \\
\text { Recognition }\end{array}$ & $\overline{\text { Normal }}$ & Normal & $\begin{array}{l}\text { Mild } \\
\text { Normal }\end{array}$ & $\begin{array}{l}\text { Moderate } \\
\text { Normal }\end{array}$ & $\overline{\text { Normal }}$ & $\begin{array}{l}\text { Moderate } \\
\text { Abnormal }\end{array}$ & $\begin{array}{l}\text { Severe } \\
\text { Abnormal }\end{array}$ & $\begin{array}{l}\text { Severe } \\
\text { Abnormal }\end{array}$ & $\begin{array}{l}\text { Moderate } \\
\text { Normal }\end{array}$ & $\begin{array}{l}\text { Mild } \\
\text { Normal }\end{array}$ \\
\hline $\begin{array}{l}\text { Ideational apraxia } \\
\text { Imitation }\end{array}$ & - & - & $\bar{M}_{\text {ild }}$ & $\overline{\text { Mild }}$ & - & $\begin{array}{l}\text { Moderate } \\
\text { Moderate }\end{array}$ & $\begin{array}{l}\text { Moderate } \\
\text { Severe }\end{array}$ & $\begin{array}{l}\text { Moderate } \\
\text { Severe }\end{array}$ & $\overline{\text { Severe }}$ & $\overline{\text { Mild }}$ \\
\hline Sequential arm movements & - & - & - & - & - & Moderate & Severe & Severe & Moderate & - \\
\hline MMSE & 30 & 30 & 30 & 30 & 30 & 30 & 17 & 10 & 26 & 28 \\
\hline
\end{tabular}


$\left(\right.$ MMSE R ${ }^{2}=0.63, \mathrm{~F}(1,8)=13.8, \mathrm{p}<0.01$; and picture arrangement $R^{2}=0 \cdot 78, F(2,7)=$ $12.3, \mathrm{p}<0.01)$. Ideational apraxia scores only correlated with MMSE scores $\left(\mathrm{R}^{2}=\right.$ $0.52, \mathrm{~F}(1,8)=7.60, \mathrm{p}<0.05)$. No significant correlations were found between the independent variables and scores of buccofacial apraxia.

Finally, the alien limb behaviour was only present in patients with apraxia (five out of seven, four with ideomotor apraxia and one with both ideomotor apraxia and ideational apraxia). Four patients showed a right alien limb and one patient had a left alien limb.

\section{Discussion}

Ideomotor apraxia was found in the less affected limb in seven out of 10 patients with corticobasal degeneration. In two patients the praxic disturbances were mild and only emerged after a comprehensive assessment. Therefore, as apraxia is a key finding for the diagnosis of corticobasal degeneration,,$^{1-5}$ the performance of pantomimes should be assessed in the less symptomatic side whenever the disease is suspected.

One limitation of any study of apraxia in corticobasal degeneration is how to examine the accuracy of learned skilled movements in patients with akinesia, rigidity, and involuntary movements. To minimise this problem, we examined the limb with less motor involvement and also assessed recognition of motor acts. If apraxia in corticobasal degeneration is related to the motor disorder rather than a "true" apraxia, there should be no association between the presence of apraxia and side of initial symptoms because, except for patients with callosal lesions, apraxia is always bilateral. We found, however, that patients who had initial symptoms in the right limb (left hemisphere dysfunction) had a significantly higher frequency of ideomotor apraxia than patients with initial symptoms in the left limb (right hemisphere dysfunction). This finding is in agreement with the fact that most right handers have the "movement formulae" or visuokinesthetic motor engrams stored in the left hemisphere, and ideomotor apraxia almost always results from left but not right hemisphere lesions. ${ }^{1011}$

According to Liepmann, the learning of a skilled motor behaviour requires the acquisition of both a "movement formulae" and an "innervatory pattern" which would convey the formulae information to the appropriate primary motor areas. ${ }^{10}$ The movement formulae are thought to be stored in the inferior parietal lobe and coded in a three dimensional supramodal code. ${ }^{11}$ The supplementary motor area, which receives strong projections from the parietal lobe, projects to the primary motor cortex and has neurons which discharge before motor neurons, is probably the structure where these space time representations are transcoded into an innervatory pattern before a skilled movement takes place. ${ }^{12} 13$
Heilman et al proposed the presence of two forms of ideomotor apraxia. In the first, patients with lesions of the left parietal lobe that damage the visuokinesthetic motor engrams develop a bilateral deficit in the production of skilled motor movements, associated with a gesture comprehensiondiscrimination disorder. The second type of ideomotor apraxia is due to left supplementary motor area damage or subcortical lesions (which disconnect motor areas from the undamaged inferior parietal lobe), and patients are able to comprehend and discriminate pantomimes flawlessly. ${ }^{11}$ Because four of our seven patients with ideomotor apraxia had normal gestural comprehension, their pattern of apraxia is in agreement with Heilman's second type. The significant correlation between the severity of ideomotor apraxia and deficits on the picture arrangement (a test of abstraction and sequencing that is usually abnormal in patients with frontal lobe deficits) further supports the role of frontal lobe dysfunction in the production of ideomotor apraxia in at least some patients with corticobasal degeneration.

Orofacial apraxia, when present, usually occurs late in the course of corticobasal degeneration, although it may rarely be the initial manifestation together with loss of speech output. ${ }^{14}$ None of our patients with ideomotor apraxia had buccofacial apraxia, however. Watson et al described two patients with left medial frontal stroke lesions (including the supplementary motor area), who demonstrated an ideomotor apraxia when tested with either arm, had normal comprehension and discrimination of pantomimes, and no buccofacial apraxia. ${ }^{13} \mathrm{~A}$ recent study by Raade $e t$ al also demonstrated quantitative and qualitative differences between limb and buccofacial praxic performance, further suggesting the presence of two different systems for skilled movements; one for planning and controlling limb movements, and another for planning and controlling buccofacial movements. ${ }^{15}$ The ventrolateral premotor area may be closely related to the second system as buccofacial apraxia mainly correlates with lesions in the frontal operculum and the anterior periventricular white matter. ${ }^{15-17}$ Both electrical stimulation and blood flow studies in humans demonstrated that the supplementary motor area is mainly responsible for limb movements and has a restricted role in nonspeech related sequential buccofacial movements. ${ }^{1218-21}$ The role of the supplementary motor area in the production of limb apraxia is also supported by the fact that the alien limb behaviour (usually produced by frontomedial lesions) was only seen among patients with corticobasal degeneration who have ideomotor apraxia.

Three patients with severe ideomotor apraxia (cases 6, 7, and 8) also had deficits in gesture comprehension and discrimination, which suggests damage to the inferior parietal lobe. All of them also showed ideational apraxia with praxic disturbances attributable to a conceptual defect or a disorder in the 
general configuration of the gesture, as they showed no response, performed irrelevant or unrecognisable movements, or produced different types of ideational or content errors when attempting to carry out serial acts. ${ }^{22}$ Roy and Square have proposed a two part system as a basis for action (praxis): a "conceptual" system that encompasses a knowledge base for action and a "production" system that provides the mechanisms for movements. ${ }^{23}$ Within this model, the syndrome of ideational or conceptual apraxia is due to failure of the conceptual praxis system (or action semantics), whereas ideomotor apraxia would result from a disruption of the production praxis system. ${ }^{24}$ Both systems interact closely as ideomotor apraxia and ideational apraxia may coexist in patients with focal lesions in the posterior region of the left hemisphere, or in patients with diffuse brain damage. ${ }^{25}$ As a matter of fact, ideational apraxia has been most often described in patients with dementia, and ideational apraxia together with aphasia and general intellectual dysfunction are commonly associated. ${ }^{22} 25-28$

There is a considerable overlap in clinical manifestations among the group of neurodegenerative disorders with ballooned achromasic neurons, because patients may present with symptoms and signs of basal ganglia dysfunction, aphasia, dementia, or a variable combination of all three. ${ }^{1-89-32}$ Until the aetiopathology of such disorders is clarified, description of their main neuropsychological features may help to establish useful criteria for clinical classification.

1 Rebeiz J, Kolodny EH, Richardson EP. Corticodentatonigral degeneration with neuronal achromasia. Arch Neurol 1968;18:20-33.

2 Case records of the Massachussetts General Hospital. N Engl $\mathcal{F}$ Med 1985;313:739-48.

3 Watts RL, Williams RS, Growdon JD, Young RR, Haley EC Jr, Beal MF. Cortico-basal ganglionic degeneration. Neurology 1985;35(suppl 1):178

4 Watts RL, Mirra SS, Young RR, Burger PC, Villier JA, Heyman A. Cortico-basal ganglionic degeneration (CBGD) with neuronal achromasia: clinicalpathological study of two cases. Neurology 1989;39 (suppl 1):140.

5 Gibb WR, Luthert PJ, Marsden CD. Corticobasal degeneration. Brain 1989;112:1171-92.

6 Riley DE, Lang AE, Lewis A, Resch L, Ashby $P$, Riley DE, Lang AE, Lewis A, Resch L, Ashby P,
Hornykiewicz O, Black S. Cortical-basal ganglionic degeneration. Neurology 1990;40:1203-12.

7 Sawle GV, Brooks DJ, Marsden CD, Frackowiak RSJ. Corticobasal degeneration. A unique pattern of regional cortical oxygen hypometabolism and striatal fluorodopa uptake demonstrated by positron emission tomography. Brain 1991;114:541-56.
8 Eidelberg D, Dhawan V, Moeller JR, Sidtis JJ, Ginos JZ, Strother SC, et al. The metabolic landscape of corticobtrother SC, et al. The metabolic landscape of corticobasal ganglionic degeneration: regional asymmetries
studied with positron emission tomography. $₹$ Neurol studied with positron emission tom
Neurosurg Psychiatry 1991;54:856-62.

9 González Rothi LJ, Mack L, Verfaellic M, Brown P, Heilman KM. Ideomotor apraxia: error pattern analysis. Aphasiology 1988;2:381-8.

10 Liepmann H. Du linke Hemisphare und das Handelin Munch. Med Wochenschr 1905;49:2375-8.

11 Heilman KM, Rothi LJG. Apraxia. In: Heilman KM. Valenstein E, eds. Clinical neuropsychology. New York: Oxford University Press, 1985:131-50.

12 Brinkman C, Porter R. Supplementary motor area in the monkey: Activity of neurons during performance of a

13 Watson R, Fleet S, González Rothi LJ, Heilman KM. Apraxia and the supplementary motor area. Arch Neurol Apraxia and the sup

14 Lang A. Cortical basal ganglionic degeneration presenting with progressive loss of speech output and orofacial dyspraxia. F Neurol Neurosurg Psychiatry 1992;55:1101.

15 Raade AS, Rothi LJG, Heilman KM. The relationship between buccofacial and limb apraxia. Brain Cogn 1991; 16:130-46.

16 Tognola G, Vignolo LA. Brain lesions associated with oral apraxia in stroke patients: a clinico-neuroradiological investigation with CT scan. Neuropsychologia 1980;18: 257-72.

17 Alexander MP, Baker E, Naeser MA, Kaplan E, Palumbo C. Neuropsychological and neuroanatomical dimensions of ideomotor apraxia. Brain 1991;115 87-107.

18 Penfield $\mathrm{W}$, Welch $\mathrm{K}$. The supplementary motor area of the cerebral cortex. Arch Neurol Psychiatry 1951;66: the cerebral

19 Orgogozo JM, Larsen B. Activation of the supplementary motor area during voluntary movement in man suggests it works as a supramotor area. Science 1979;206:847-50.

20 Fried I, Katz A, McCarthy G, Sass KJ, Williamson P, Spencer SS, Spencer DD. Functional organization of the human supplementary motor cortex studied by electrical stimulation. F Neurosci 1991;11:3656-66.

21 Ikeda A, Lüders HO, Burgess RC, Shibasaki H. Movement-related potentials recorded from supplementary motor area and primary motor area. Role of supplementary motor area in voluntary movements. Brain 1992;115:1017-43.

22 De Renzi E, Lucchelli F. Ideational apraxia. Brain 1988; 111:1173-85.

23 Roy EA, Square PA. Common considerations in the study of limb, verbal, and oral apraxia. In Roy EA, ed. Advances in psychology. Neuropsychological studies of Advances in psychology. Neuropsychological studies of apraxia and related disord

24 Rothi LJG, Ochipa C, Heilman KM. A cognitive neuropsychological model of limb praxis. Cogn Neuropsychol $1991 ; 8: 443-58$

25 Ochipa C, Rothi LG, Heilman KM. Conceptual apraxia in Alzheimer's disease. Brain 1992;115:1061-71.

26 Pick A. Studien über Motorische Apraxie und ihr Nahestehende Erscheinungen: ihre Bedeutung in der Symptomatologie Psychopathischer SymptomenKomplexe. Leipzig: Deuticke, 1905.

27 Denny-Brown D. The nature of apraxia. 7 Nerv Ment Dis 1958;126:9-32.

28 Ajuriaguerra J De, Hecaen $H$, Angelergues $R$. Les Apraxies: varietes cliniques et lateralisation lesionnelle. Rev Neurol 1960;102:566-94.

29 Lippa CF, Cohen R, Smith TW, Drachman DA. Primary progressive aphasia with focal neuronal achromasia.

30 Clark A, Manz HJ, White CL, Lehmann J, Miller D, Coyle JT. Cortical degeneration with swollen chromatolytic neurons: Its relationship to Pick's disease. tolytic neurons: Its relationship to Pip

31 Constantinidis J. Pick dementia: Anatomoclinical correlations and pathophysiological considerations. Interdisciplinary Topics in Gerontology 1985;19:72-97.

32 Lippa CF, Smith TW, Fontnean N. Corticonigral degeneration with neuronal achromasia: A clinico pathologic study of two cases. $\mathcal{F}$ Neurol Sci 1990;98:301-10. 